\title{
A Theory of No-Thing
}

André de Vinck

\begin{abstract}
How can we define a new general theory of evolution and, consequently, a new general theory of evolutionary history? First, we have to solve the mystery that lies at the heart of Darwin's great book. Second, we have to trace the beginnings of nature-culture-history. Darwin couldn't define the term species and his successors can't define the term gene. A standard solution to this dilemma is to define a species as a group of dimorphic organisms that successfully exchange genes. However, one undefinable thing can't be used to define another undefinable thing. Instead of tracing the evolution of undefinable things, we can trace the evolution of definable relations-e.g. exchange. To exchange means to put in relation and, therefore, to signify the relative values of the signifiers being exchanged as well as the relative values of the signifiers initiating the exchange. In this context I s uggest that nature begins with the dynamic of exchange, culture begins with the practice of exchange, history begins with the syntax of exchange. Instead of a theory of every-thing, therefore, I propose a theory of no-thing. I propose that no-thing exists in and of itself and that every-thing evolves as a co-incidental eco-matrix of the signifying relations of exchange.
\end{abstract}

\section{Key Words}

evolutionary history, exchange theory, complexity, reflexivity, theory of nothing, theory of no-thing, theory of everything, origin of culture.

Correspondence |André de Vinck, jdv327@earthlink.net

Citation | de Vinck, A. (2018) A Theory of No-Thing. Journal of Big History, III(1); 95 - 114.

DOI | http://dx.doi.org/10.22339/jbh.v3i1.3150

ow can we define a new general theory
of evolution and, consequently, a new general theory of evolutionary history? First, we have to solve the mystery that lies at the heart of Darwin's great book. Second, we have to trace the beginnings of nature-culture-history.

In the "Introduction" to On the Origin of Species (1859), Darwin summarizes his Malthusian theory of evolution: "As many more individuals of each species are born than can possibly survive; and as, consequently, there is a frequently recurring struggle for existence, it follows that any being, if it vary however slightly in any manner profitable to itself, under the complex and sometimes varying conditions of life, will have a better chance of surviving, and thus be naturally selected. From the strong principle of inheritance, any selected variety will tend to propagate its new and modified form" $(O S, 6)$. In this way Darwin answers the question posed by his title: The origin of species can be traced to the evolutionary dynamic of multiplication and variation, selection and adaptation. He fills in the details of that dynamic in the rest of his great book. Case closed.

And yet, not so fast. In fact, the case remains open because the mystery that lies at the heart of Darwin's great book remains unsolved. We can begin again with the question posed by Darwin's title: What is the origin of species? When Darwin tries to define his basic terms, he acknowledges that, "Certainly no clear line of demarcation has yet been drawn between 
a species and a sub-species...or again between a subspecies and well-marked varieties, or between lesser varieties and individual differences" (OS, 44). And then he admits that, "I look at the term species, as one arbitrarily given for the sake of convenience to a set of individuals closely resembling each other, and that it does not essentially differ from the term variety, which is given to less distinct and more fluctuating forms. The term variety, again, in comparison with mere individual differences, is also applied arbitrarily, and for mere convenience sake" $(O S, 45)$. In other words, Darwin admits that he can't distinguish a species from a sub-species, a sub-species from a variety, a variety from a difference. He admits that what he and his fellow naturalists define as the essential identity of a species is in fact nothing more than a convenient collection of the formal similarities of an arbitrary group of apparent differences. He admits that a species is undefinable. In short, in the second chapter of his great book, Darwin confronts the radical implications of his radical theory of evolution: i.e. the origin has no originality and the species has no specificity. And so Darwin's title, On the Origin of Species, along with the question posed by it, is fantastically ironic. And here we confront the mystery that lies at the heart of his great book: If it isn't the species that is evolving, then what exactly is evolving?

Darwin was primarily an empirical field biologist, an empirical laboratory researcher, an empirical natural historian. He was only secondarily, and quite hesitantly, an evolutionary theorist. And no wonder he hesitated-given the religious authority of biblical history in mid $19^{\text {th }}$ century England and Europe. He finally presented and published his Malthusian theory of evolution only after Wallace sent him an outline of his own, independently articulated, version of it. Even so, Darwin continued to struggle with the radical implications of his radical theory throughout his great book. He recognizes, for example, that the temporal flow of evolutionary history undermines the spatial table of natural history as well as the vertical ladder of metaphysical history. Specifically, he recognizes that if the never-ending temporal flow of apparent differences admit "no clear line of demarcation," then he and his fellow naturalists have to abandon Linnaeus' spatial table of formal similarities and Lamarck's vertical ladder of essential identities. However, instead of pursuing the radical implications of his radical theory, Darwin immediately retreats from them. He tries to jam his temporal theory of evolutionary history back into Linnaeus' spatial theory of natural history. And, as we shall see, he ultimately tries to hoist his evolutionary history of apparent differences and Linnaeus' natural history of formal similarities back up the ladder of Lamarck's metaphysical history of essential identities. And he huffs and puffs with all kinds of qualifications and rationalizations as he struggles to achieve that goal.

Immediately after admitting that he can't draw the lines which demarcate a difference, a variety, a sub-species, a species, Darwin returns to the task of drawing those lines. That is, he returns to the task of drawing up the spatial tables of natural history: "I thought that some interesting results might be obtained in regard to the nature and relations of the species which vary most, by tabulating all the varieties in several well-worked floras" $(O S, 45)$. Although he recognizes some of the difficulties involved in drawing up these new spatial tables in the context of his new temporal theory, he announces that, "I shall reserve for my future work the discussion of these difficulties..." $(O S, 45)$. In other words, Darwin puts off the question of time for another time because he doesn't have time to address it-and because he doesn't know how to address it. He releases the temporal genie of evolutionary history from the spatial constraints of natural history and then he tries to put that genie back into the bottle-or, in this case, back into the Linnaean box. And so, not surprisingly, the general conclusions he draws from his new natural-historical tables are fraught with evolutionary-historical equivocations. He states, "Hence it is...the dominant species...which most oftenest produce well-marked varieties, or as I consider them, incipient species" $(O S, 46)$. He recalls, 
"We have seen that there is no infallible criterion by which to distinguish species and well-marked varieties..." $(O S, 48)$. And so he struggles with the contradictions of the spatial framework that he tries to re-impose on his temporal narrative.

In this context Darwin turns to the rationalizations of analogy and averages. He explains that when he and his fellow naturalists consider two related varieties, they "...are compelled to come to a determination by the amount of difference between them, judging by analogy whether or not the amount suffices to raise one or both to the rank of species" (OS, 48). And he agrees with his colleagues who suggest that "...in regard to plants...and insects...the difference between species is exceedingly small." He continues, "I have endeavoured to test this numerically by averages..." $(O S, 48)$. And yet again he acknowledges that, "Finally, then, varieties have the same general characters as species, for they cannot be distinguished from species..." $(O S, 49)$. While the temporal streams of a Darwinian evolutionary history of apparent difference cannot be contained within the spatial grids of a Linnaean natural history of formal similarity, or, for that matter, sustained by the vertical steps of a Lamarckian metaphysical history of essential identity, nevertheless Darwin keeps returning to Linnaeus' grids and, ultimately, Lamarck's steps. And, again, Darwin is primarily an empirical field biologist, an empirical laboratory researcher, an empirical natural historian. Whenever he confronts the radical thought of the non-identity of non-identity, he quickly retreats to his empirical presuppositions. And we can only admire the way in which he struggles to give birth to his radical Neo-Socratic rhetorical theory of evolutionary history in the context of Linnaeus' moderate NeoAristotelean grammatical theory of natural history and Lamarck's conservative Neo-Platonic logical theory of metaphysical history.

At the end of his great book Darwin once again returns to the Neo-Socratic rhetoric of the non-identity of non-identity-i.e. to the temporal streams of the fluctuating appearances of difference. He concludes,
"In short, we shall have to treat species in the same manner as those naturalists treat genera, who admit that genera are merely artificial combinations made for convenience. This may not be a cheering prospect; but we at least will be freed from the vain search for the undiscovered and undiscoverable essence of the term species" (OS, 392). Darwin admits, once again, that there is no such thing as a distinctly identifiable species that can be clearly demarcated. And yet he doesn't take the next step. He doesn't admit that since he can't define a species, then he can't discover the origin of species. Instead, at the end of his great book, he invokes a radical Neo-Socratic rhetoric of the exigency of appearance-e.g. " ...but at least we will be freed from the vain search for the undiscovered and undiscoverable essence of the term species" (OS, 392); a moderate Neo-Aristotelian grammar of the teleology of form-e.g. "And as natural selection works solely by and for the good of each being, all corporeal and mental endowments will tend to progress toward perfection" $(O S, 395)$; and a conservative Neo-Platonic logic of the ontology of essence-e.g. "Therefore I should infer from analogy that probably all the organic beings which have ever lived on this earth have descended from some one primordial form, into which life was breathed by the Creator" (OS, 391). In fact, recent genetic research does suggest that all living animals did evolve from a common ancestor that existed about 650 million years ago. Paps and Holland "...using extensive genome comparisons...infer the minimal protein-coding genome of the first animal..." (NC, $04 / 30 / 18$ ). In a remarkable feat of devolutionary genetics, they infer the identity of 6,331 genes in that primeval genome. However, it requires a leap of faith, a great chain of being, or a ladder of metaphysics to get from that primeval genome to what Darwin calls the breath of the Creator.

Derrida would say that the structural logic of Darwin's metaphysical history and the phenomenal rhetoric of Darwin's evolutionary history deconstruct one another. According to Derrida, every text is a battle of wits between the King of Logic and the Jester of 
Rhetoric, between the tragedy of Lear and the comedy of the Fool, between the structure of meaning and the phenomena of interpretation. As a result, every text tumbles into the postmodern abyss of signification. And yet we should note that it is Derrida himself who opens up that postmodern abyss when he brackets and elides the functional grammar of the narrative. It is Derrida himself who breaks the grammatical link between logic and rhetoric. Why does he break that link? He does so in order to reveal how the ploy of logic constructs the hierarchies of meaning in the text and how the play of rhetoric undermines the hierarchies of interpretation in the mind. However, Derrida pays a high price for his deconstructive phenomenological revelations. He throws every text into the postmodern abyss of signification that can't be bridged by the narratives of history.

Instead of deconstructing the binary opposition of Darwin's structural logic and his phenomenal rhetoric, therefore, I want to rehistoricize the trinary economy of Darwin's structural logic, functional grammar, phenomenal rhetoric. I want to suggest that when Darwin confronts the phenomenal rhetoric of apparent difference-i.e. the non-originality of origin, the nonspecificity of species, the non-essentiality of essencehe retreats from that phenomenal rhetoric by writing a new version of Linnaeus' functional grammar of formal similarity and a new version of Lamarck's structural logic of essential identity. In edition after edition of his great book, Darwin struggles to reconcile his version of his temporal evolutionary history with his version of Linnaeus' spatial natural history and his version of Lamarck's hierarchical metaphysical history. However, his attempt to reconcile the rhetoricgrammar-logic of his evolutionary narrative fails. As a result, the mystery that lies at the heart of his great book remains unsolved: If it isn't the species that is evolving, then what exactly is evolving?

Darwin knew there was an underlying logic to the evolutionary process of descent with modification, but he admits that, "...the laws governing inheritance are quite unknown..." $(O S, 13)$. And so he falls back on generic euphemisms. He refers to "the strong principle of inheritance" $(O S, 6)$. He wonders, "Whatever the cause may be of each slight difference in the offspring..." $(O S, 139)$. And he cites, "The complex and little known laws governing variation..." (OS, 381). Of course, Darwin knew nothing about genetics. Mendel started to breed his pea plants in 1854, but he didn't publish his results until 1866-seven years after Darwin published his great book. An uncut copy of Mendel's obscure journal article was found in Darwin's library (Henig, $M G, 143$ ). Presumably, Mendel had sent him a copy and, evidently, Darwin never read it. Instead of focusing on the genetic logic of modification as articulated in multiple generations of pea plants, Darwin begins his discussion of evolution with the generic laws of modification as articulated in multiple generations of pigeons. Mendel bred pea plants, Darwin bred pigeons. And while Darwin didn't even understand how the generic laws of modification worked-he thought offspring more or less averaged the traits of their parents-he did recognize that he and his fellow pigeon breeders could manipulate the logical laws of modification via the grammatical rules of selection. That is, he and his fellow breeders selected and mated birds with the traits they wanted and, in this way, they further domesticated the natural logic of modification, the natural grammar of selection, the natural rhetoric of adaptation. And yet Darwin still couldn't distinguish a set of differences from a variety, a variety from a sub-species, a sub-species from a species.

In fact, the entire argument of Darwin's ironically titled book, On the Origin of Species, proves that there is no such thing as the origin of species. There is no such thing as a distinction, a variety, a species with an origin-essence-identity. The often elided preposition that begins Darwin's title reminds us that Darwin does not actually discover the origin of species, rather he describes an evolutionary dynamic that undermines the very idea of an original origin, a specified species, an essential essence. And so he struggles to work out a new evolutionary-historical economy of the logic- 
grammar-rhetoric of the modification-selectionadaptation of distinctions-varieties-species. And, again, he does not succeed. In one paragraph he advances his radical evolutionary history, in the next paragraph he returns to Linnaeus' moderate natural history. And, in the end, he even returns to Lamarck's conservative metaphysical history. While Darwin doesn't pursue the radical implications of his radical theory, we are pursuing them. If it isn't the essential identity of a species that is being modified-selectedadapted over and again down the ages, then what, exactly, is evolving?

The rediscovery of Mendel's work at the turn of the $20^{\text {th }}$ century and the genetic revolution that followed seemed to solve the mystery that lies at the heart of Darwin and Wallace's theory. Mendel discovered the genetic logic-i.e. the mathematic ratios-of specific traits passed down from one generation of pea plants to another. And that genetic logic seemed to be the missing logic-the missing principle, cause, lawof variation that Darwin did not understand. And therefore, we might conclude, it is precisely the gene-the quintessential unit of evolution-that is being modified-selected-adapted down the ages. However, a funny thing happened on the way to the genetics lab. Just as Darwin realized that he couldn't define a species, so too several leading geneticists have realized that they can't define a gene. What, exactly, is a gene? Should it be defined in terms of its structural configuration, its functional operation, its phenomenal articulation? Should it be defined in terms of its chromosomal location, its cellular manifestation, its somatic generation? What parts of DNA are parts of genes, what parts of DNA are not parts of genes? Just as Darwin ultimately abandons the search for "... the undiscoverable essence of the term species" (OS, 392), so too several leading geneticists now agree "... there is no longer a precise definition of what could count as a gene" (Rheinberger et al., SEP, 2015). In short, the more closely we examine the boundary of identity, the more quickly it diffuses into a cloud of difference. Of course, just as Darwin fell back on the fuzzy logic of analogy and averages in order to develop an approximate science of the modificationselection-adaptation of species, so too we can fall back on that same fuzzy logic in order to develop an approximate science of the modification-selectionadaptation of genes. However, that stopgap measure still does not solve the mystery that lies at the heart of Darwin-Wallace-Mendel's theory: What, exactly, is evolving? What, exactly, is being modified-selectedadapted?

In contrast to Darwin's nervous critique of the essential identity of a species, Klein opens The Human Career (2009)-his comprehensive textbook survey of recent advances in evolutionary anthropology-with the confident assertion that, "The species is the least arbitrary and the most fundamental evolutionary unit, and it must be understood before any consideration of evolution, even one focused tightly on a single species like Homo sapiens" (HC, 1). Why was Darwin so nervously critical of the idea of the essential identity of a species and why is Klein so confidently certain of it? Precisely because Darwin knew nothing about genetics and Klein knows a lot about it. Klein explains that, "...no matter how detailed the resemblances between two groups of organisms, if individuals cannot exchange genes between groups, the two populations must be assigned to different species" $(H C, 1)$. In other words, a species can be defined as a fertile group of dimorphic organisms that successfully exchange genes. And most evolutionary biologists and most evolutionary anthropologists would acknowledge the pragmatic efficacy of that working definition. However, if a species is undefinable and if a gene is undefinable, then one undefinable thing can't be used to define another undefinable thing. In other words, as the Hindu myth suggests, if the flat earth rests on the back of an elephant and if that elephant stands on the back of a turtle and if that turtle stands on the back of another turtle, then it's turtles all the way down. In this context we can take Darwin-Wallace-Mendel's theory of evolution another step forward by solving the mystery that lies at the heart of their argument. 
$* * * * * * * * * *$

Instead of tracing the evolution of undefinable thingse.g. species, varieties, genes-we can trace the evolution of definable relations-e.g. exchange. To exchange means to put in relation and, therefore, to signify the relative values of the signifiers being exchanged as well as the relative values of the signifiers initiating the exchange. The relative value of value can be understood as the range of the more optimal and the less optimal ecological articulations of the signifying relations of exchange. In this context I suggest that nature begins with the dynamic of exchange, culture begins with the practice of exchange, history begins with the syntax of exchange. Specifically, I suggest that the signifying relations of exchange evolve the evolutionary algorithms of exchange which evolve the eco-matrices of exchange which evolve, for example, our so called species. In turn, we objectify the co-incidental micro-median-macro eco-matrices of exchange and we call them strings-membranesquarks; we call them atoms-molecules-cells; we call them genes-varieties-species; we call them life-mindlanguage; we call them nature-culture-history. Instead of searching for the mythical origin of nature-culturehistory, therefore, I suggest that we can trace the long evolutionary history of the signifying relations of exchange. And so, to be clear, in this study I am not talking about all the many, varied signifying relations of this universe, rather I am talking about one particular kind of signifying relation: i.e. exchange.

Of course, as a result of the linguistic turn of $20^{\text {th }}$ century cultural theory, the signifying relations of exchange-as signifying relations-have inspired a vast literature that cuts across the disciplines. I will review and critique a select portion of that literature in the future, but, in the meanwhile, I will cite three key examples in order to clarify and distinguish my theory. In The Elementary Structures of Kinship (1949), Lévi-Strauss outlines a universal structurallogical system of exchange that he projects into the unconscious cybernetic mind. In The Order of
Things (1966), Foucault outlines a general functionalgrammatical system of exchange that he projects into the preconscious taxonomic mind. In Given Time: I. Counterfeit Money (1991), Derrida outlines a particular phenomenal-rhetorical system of exchange that he projects into the conscious linguistic mind. In other words, just as Lamarck, Linnaeus, Darwin fetishize, respectively, the logic, grammar, rhetoric of the narratives of natural history, so too Lévi-Strauss, Foucault, Derrida fetishize, respectively, the logic, grammar, rhetoric of the narratives of cultural history. As a result, both the modern natural historians and the modern cultural historians fail to put the evolutionaryhistorical narratives of nature-culture-history back together again. Lévi-Strauss reduces what he defines as the surface rhetorical level of phenomenal history to what he defines as the deep logical level of structural psychology; Foucault reduces what he defines as the surface rhetorical level of phenomenal history to what he defines as the median grammatical level of functional epistemology; Derrida reduces what he defines as the surface rhetorical level of phenomenal history and the deep logical level of structural psychology to a binary opposition that deconstructs itself. In this way Lévi-Strauss, Foucault, Derrida reduce the evolutionary-historical narratives of cultural history to, respectively, a spatialized, ahistorical, structurallogical system of exchange, functional-grammatical system of exchange, phenomenal-rhetorical system of exchange.

In this context I suggest that we can make three moves that will enable us to put the evolutionary-historical narratives of nature-culture-history back together again: 1.) We can decenter language by recognizing that while it is an exquisitely expressive mode of exchange, while it is the medium of thought, speech, writing, while it is the medium of this very sentence, nevertheless language is just one more articulation of the long evolutionary history of the signifying relations of exchange. 2.) We can shift the focus of cultural theory from the $20^{\text {th }}$ century linguistic turn to a $21^{\text {st }}$ century evolutionary-historical reflexivity. 3.) We can 
write a reflexive, critical, postmillennial theory of the long evolutionary history of the signifying relations of exchange. That is, while we define and filter our knowledge of the world in and through language and its categories, nevertheless we can decenter language and its categories in a broader evolutionary-historical context. Instead of universalizing the semiotics of language, we can generalize the semiotics of natureculture-history. Instead of refetishizing spatialized, ahistorical, structural-logical systems, functionalgrammatical systems, or phenomenal-rhetorical systems of exchange, we can write reflexive, critical, postmillennial, evolutionary-historical narratives of the signifying relations of exchange. That is, we can re-integrate the logic-grammar-rhetoric of exchange in the evolutionary-historical narratives of evolutionary history.

In short, I suggest that we can advance Darwin, Wallace, Mendel's theories of nature by shifting our attention from the empirical identifications of species, varieties, genes to the evolutionary articulations of the signifying relations of exchange. We can advance Lévi-Strauss, Foucault, Derrida's theories of culture by shifting our attention from the spatialized frameworks of the logical, grammatical, rhetorical systems of exchange to the evolutionary histories of the signifying relations of exchange. We can advance Hegel, Marx, Nietzsche's theories of history by shifting our attention from the mechanical dialectic of mind, matter, morality to the evolutionary algorithms of the signifying relations of exchange. In turn, I suggest we can advance the current theories of complexity by shifting our attention from the phenomenal-structural emergence of complexity to the evolutionary-historical evolution of reflexivity. We will come back to these theories of nature-culturehistory and reflexivity throughout the course of this study.

Instead of a theory of every-thing, therefore, I propose a theory of no-thing. Specifically, I suggest that the signifying relations of exchange looped back on themselves over and again down the ages and evolved the evolutionary algorithms of exchange which, in turn, looped back on themselves over and again down the ages and evolved the eco-matrices of exchange which, in turn, looped back on themselves over and again down the ages and evolved, for example, our so called species. In turn, we objectify the co-incidental micro-median-macro eco-matrices of exchange and we call them nature-culture-history. And in this context a new general theory of evolution leads to a new general theory of evolutionary history. The exchange of genes, the exchange of goods, the exchange of greetings, for example, are already very late articulations of nature-culture-history. And so instead of reducing the universe to a static formal table of empirical objectified things, we can recognize the universe as a co-incidental eco-matrix-or, rather, as a vast interactive network of co-incidental micromedian-macro eco-matrices-of the signifying relations of exchange. And with this very argument the long evolutionary history of these co-incidental eco-matrices loops back on itself in and through our so called species and evolves the reflexive consciousness of evolutionary history.

In this context I suggest that every so called thing that evolves from the long evolutionary history of the signifying relations of exchange is, well, relative. That is, no-thing exists in and of itself. And no-thing exists in and of itself because no-thing has a pure origin, pure essence, pure identity. And no-thing has a pure origin, pure essence, pure identity because everything evolves from the particular energetic-material and material-energetic, temporal-spatial and spatialtemporal intersections-pathways-networks of the signifying relations of exchange. We can define a so called tree as an object or a thing, for example, only if we completely ignore the fact that what we attempt to fix and to name as a so called tree is actually the evolutionary-historical co-incidence of countless signifying relations of earth, air, fire, water interacting in a particular eco-historical time and eco-geographic place. And we can define a so called tree as an object or a thing only if we completely ignore the fact that the very word "tree" is actually the evolutionary-historical co-incidence of countless signifying relations of 
sounds, pauses, letters, signs interacting in a particular socio-historical time and socio-linguistic place. And we can define a so called tree as an object or a thing only if we completely ignore the fact that what we call the consciousness, perception, identity, perspective of what we call the subject who views what we call the object of the so called tree are also the evolutionaryhistorical co-incidences of countless signifying relations of signifiers interacting in a particular cultural-historical time and cultural-cognitive place. And we can define a so called tree as an object or a thing only if we completely ignore the fact that we are exchanging signifiers from here to here and from now to now along the temporal-spatial and spatial-temporal syntactic pathway of this particular sentence which also happens to link the here-there-everywhere as well as the past-present-future of the places and times where and when this sentence is being written and the places and times where and when it will be read. And so, like Whitman addressing the future generations, "Crossing Brooklyn Ferry," I am addressing the future generations crossing the syntactic ferry of this very sentence. Greetings fellow travelers! We are the time beings! In the time being, the time being now, the time being lives and dies: giving and taking, losing and keeping-a syntax unfolding the narratives of time. In other words, Heidegger got it all wrong: it isn't being and time, rather it's the time being. And as the time being we can study the time being in the hermeneutical mirror of evolutionary history.

A postmillennial painting of a so called tree standing alone in a meadow, therefore, might be a neo-pointillist abstraction which reminds us of the countless energetic-material and temporal-spatial co-incidental interactions of the countless signifying relations of exchange evolving the countless relative-complexreflexive levels-dimensions-scales and velocities of physics-chemistry-biology, economics-sociologyhistory, anthropology-psychology-art history, etc., etc. And the painting might also be a blank canvas-because we might have missed the co-incidental bus, because we might have missed the co-incidental articulations of the energetic-material and temporal-spatial eco-matrix of the signifying relations of exchange which define what we retrospectively nominate as the so called universe, nature, tree; self, consciousness, perception; subject, verb, object; sentence, word, signifier; dot, dot, dot and dot and then no-thing but white space.... That is, the painter might be standing in an empty meadow where a magnificent oak tree once stood and where a magnificent oak tree will one day stand. And so the painter might be standing in the blank white space of the present where the energetic-material and temporal-spatial co-incidental eco-matrices of the signifying relations of exchange that evolve what we call a magnificent oak tree no-longer-and-notyet exists. In this context we can explore the radical evolutionary-historical implications of the radical evolutionary-historical thought of the origin which has no originality, the species which has no specificity, the essence which has no essentiality. We can explore the radical evolutionary-historical implications of the no-thing-ness of no-thing-ness.

And so it should be clear that the evolutionary history of the no-thing-ness of no-thing-ness is not the same so called thing as the existential phenomenology of nothingness, because, as King Lear says in response to the Fool, "Nothing comes from nothing!" Instead, the evolutionary history of the no-thing-ness of no-thingness is the evolutionary history of the co-incidental signifying relations of exchange, evolutionary algorithms of exchange, eco-matrices of exchange. In this way we are shifting the attention of enlightened science from the spatialized grids of empirical things to the evolutionary histories of signifying relations. Of course, no matter how many times we make the distinction between the no-thing-ness of no-thing-ness and the nothingness of nothingness, this argument will be, undoubtedly, re-interpreted in some quarters as yet another version of postmodern existential phenomenology. And yet in contrast to the Heideggerian phenomenology of the emergence of being-and in contrast to all the other natural scientific, social scientific, humanistic theories of the essential 
structural logic, formal functional grammar, apparent phenomenal rhetoric of the so called universe-I am proposing an evolutionary-historical theory of the astonishingly intricate signifying relations of exchange that connect every-thing as no-thing. And since this postmillennial theory reveals how everything is no-thing, then it reveals how every-thing is intricately connected to every-thing else in the co-incidental local-global-universal micro-medianmacro eco-matrices of the signifying relations of exchange. Instead of outlining a reductive, economic, neoclassical theory of the systemic rational logic of signification or a reductive, textual, postmodern theory of the endless ahistorical deconstruction of signification, I am outlining a reflexive, critical, postmillennial theory of the long evolutionary history of the signifying relations of exchange.

As a result, we are pushing right up against the very limits of the analytically inclined Anglo-Saxon language. And so we might recall that there are other languages which enable other cultures to understand and represent themselves and the so called universe in different ways. The Navaho language, for example, articulates all kinds of nominative distinctions which make sense of the world and yet the Navaho sentence is dominated by the verb phrase. In The Navajo Language (1942), Young and Morgan explain, "The Navajo verb, unlike the English, often contains within its structure not only the verbal idea, but also the subject and object pronouns, and many adverbial modifiers. It is, in itself, a complete sentence" $(N L, 41)$. In fact, even many so called Navaho nouns are rooted in verb phrases. In $A$ Vocabulary of Colloquial Navajo (1951), Young and Morgan explain that the Navaho word for brother or sister, for example, means literally, "I came out with him/her" (VCN, 37). The Navaho word for father's clan means literally, "I am one born for it," while the Navaho word for mother's clan means literally, "I am one born to it" $(V C N, 98)$. As Young and Morgan note, "Members of a clan consider themselves to be related as members of an extended family...although in the white man's way of reckoning they are wholly unrelated" $(V C N, 255)$. Furthermore, the clan name of a person not only evokes her or his relations with an extended family, but also with an extended ecology: e.g. "the water-flows-together people," "the line-ofwillows-extended-out-gray people," "the two-rockssit people," etc. ( $V C N, 443-45)$.

Unfortunately, Young and Morgan reduce the synthetic fluidity of Navaho grammar and vocabulary to the analytic rigidity of Anglo-Saxon grammar and vocabulary-except when they occasionally offer what they call, somewhat condescendingly, literal translations. They insist on citing and translating the infinitive form of the Navaho verb phrase, for example, when clearly the participial form would be so much more evocatively accurate. While they recognize how difficult it is to translate one cultural sensibility into another cultural sensibility, nevertheless the analytic framework of their Anglo-Saxon textbooks offers only a few glimpses of the Navaho's synthetic sensibility. Similarly, the Anglo-Saxon translations of Navaho narratives impose the same analytic grid of subject-verb-object on the synthetic flow of the verb phrase-thus all but annihilating the distinctive Navaho sensibility of the interconnected, interrelational, interdynamic cosmos. In other words, the good intentions of the ethnographers, grammarians, translators sometimes leads to the sad results of cultural appropriation. Hopefully, new synthetic ethnographies, grammars, translationswritten by the Navaho people themselves-can offer new ways to evoke the Navaho's synthetic sensibility. The point being that the Navaho language enables the Navaho people to evoke the interconnections of the signifying relations of exchange in ways that are not entirely available in the English language.

The Navaho language helps us recognize, for example, that instead of being bedazzled by the so called miracle of the exact numeric ratios of the exact exchange relations of energy and matter, time and space of this particular universe which were necessary for the very possibility of the evolution of life on earth, in fact the evolution of life on earth articulates the exact numeric ratios of the exact exchange relations of energy and matter, time and space of this particular 
universe. That is, the particular signifying relations of exchange which evolved the particular evolutionary algorithms of exchange which evolved the particular eco-matrices of exchange which evolved the particular metabolic articulations of exchange-or what we call life-are part and parcel of the long evolutionary history of the signifying relations of exchange that evolved, and that continue to evolve, this particular universe. In turn, our particular so called species is yet another evolutionary-historical articulation of these same signifying relations of exchange-which are becoming reflexively conscious of themselves in and through us. And that is precisely why our mathematic algorithms correspond to this universe's mathematic algorithms. Why? Because, as the Navaho might say, we are born to this universe. We are reflexive articulations of it.

In other words, we don't have to evoke the secretions of the Cartesian pineal gland, the spirits of a Hegelian dialectical history, the sensations of a Heideggerian phenomenological consciousness in order to connect mind and body, idea and fact, science and nature. Instead, we can note that the long evolutionary history of the signifying relations of exchange loops backward on itself over and again down the ages and pulses forward the evolutionary algorithms of life-mind-language. That is, every so called speciesincluding ours-evolves from the signifying relations of exchange of this particular universe and every so called species-including ours-further evolves these signifying relations. And if we are signifying relations of exchange made reflexively conscious, then it should not be too surprising to discover that our mathematic algorithms of exchange correspond to this universe's mathematic algorithms of exchange. And so instead of being locked into our Anglo-Saxon analytic language, I suggest we can turn to the Navaho's synthetic language-specifically, to their fluidic participial phrases. Instead of defining the universe as an objectified thing, for example, I suggest we can define the universe as an energy-matter-exchangingtime-space-evolving-no-thing-ness-of-no-thingness. In this context we can recognize that energy is temporalized matter and matter is spatialized energy.
We can recognize the plastic fluidity of the signifying relations of exchange. And we can recognize our clan name: we are the energy-matter-exchangingtime-space-evolving-no-thing-ness-of-no-thing-ness people.

And so I suggest, once again, that nature begins with the dynamic of exchange, culture begins with the practice of exchange, history begins with the syntax of exchange. Nature begins with the dynamic exchange of energy and matter, culture begins with the practical exchange of signifiers and signifieds, history begins with the syntactic exchange of time and space. And yet that raises the next question: How, exactly, do the signifying relations of exchange evolve? I suggest that the innovative-generative algorithms of multiplication and variation loop back on themselves and evolve the conservative-restrictive algorithms of selection and adaptation. In other words, the more successful signifying relations of exchange are repeated more regularly, the less successful signifying relations of exchange are repeated less regularly. Success, in this context, refers to the relative value of the more optimal ecological articulations of exchange. As a result, the more successful signifying relations of exchange evolve the selection criteria of exchange and the selection criteria of exchange evolve the more successful signifying relations of exchange. They are modified-selected-adapted over and again down the ages as they continue to evolve new algorithms of exchange.

In short, as the more successful signifying relations of exchange loop back on themselves over and again, they evolve new relative algorithms which evolve new complex algorithms which evolve new reflexive algorithms. In turn, these new relative-complexreflexive algorithms of the signifying relations of exchange loop back on themselves and evolve new levels-dimensions-scales and velocities of exchange. In this way the relatively less complex co-incidental micro-median-macro eco-matrices of the energymatter-exchanging-time-space-evolving-no-thingness-of-no-thing-ness sometimes evolve the relatively more complex co-incidental micro-median-macro 
eco-matrices. The relative algorithms of energy and matter, for example, evolve the complex algorithms of stars and planets. However, it is only when the relatively complex algorithms of exchange evolve the reflexively complex algorithms of exchange that the metabolism of exchange-i.e. life-evolves. In this context I suggest that just as the dominance hierarchies of the logic-grammar-rhetoric of exchange have defined the dominant theories of nature-culturehistory, so too they have defined the dominant theories of relativity-complexity-reflexivity.

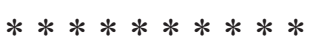

In his book, At Home in the Universe (1995), Kauffman notes that, "Most of my colleagues believe that life emerged simple and became complex. They picture nude RNA molecules replicating and replicating and eventually stumbling on and assembling all the complicated chemical machinery we find in a living cell. Most of my colleagues also believe that life is utterly dependent on the molecular logic of template replication, the A-T, G-C Watson-Crick pairing...." Kauffman continues, "I hold a renegade view: life is not shackled to the magic of template replication, but based on a deeper logic. I hope to persuade you that life is a natural property of complex chemical systems, that when the number of different kinds of molecules in a chemical soup passes a certain threshold, a selfsustaining network of reactions-an autocatalytic metabolism-will suddenly appear. Life emerged, I suggest, not simple, but complex and whole, and has remained complex and whole ever since..." (AHU, 478). We can translate Kauffman's somewhat confusing terms into the somewhat clearer terms of our evolutionary-historical theory of the logic-grammarrhetoric of the signifying relations of exchange.

In effect, Kauffman argues that most biologists believe that the surface rhetoric of the phenomenal emergence of life can be reduced to the median grammar of the functional template of DNA. However, he wants to take that standard argument a step further. He suggests that the median grammar of the functional template of
DNA can be further reduced to the deep logic of the structural interactions of chemicals. In fact, he argues that the phenomenal rhetoric of life emerges directly from the structural logic of chemicals. That is, he explicitly rejects the mediating role of the functional grammar of genetics: "I hold that life, at its root, does not depend on the magic of Watson-Crick base pairing or any other specific template replicating machinery" $(A H U, 50)$. Kauffman, like Derrida, explicitly rejects the mediating role of a functional grammar. While Derrida goes on to deconstruct the binary oppositions of phenomenal rhetoric and structural logic, Kauffman goes on to reconstruct their working relationship. He suggests that life emerges "whole" from the "phase transition" of relatively less complexly interactive chemicals to relatively more complexly interactive chemicals $(A H U, 48)$. In other words, he suggests that the phenomenal rhetoric of life emerges directly from the structural logic of self-organizing, autocatalytic, interactive chemical systems. And that is precisely why Kauffman must evoke a bit of his own stage magic. He must evoke the magical metaphor of a "phase transition." Why? Precisely because that magical metaphor enables him to leap from the deep structural logic of chemicals to the surface phenomenal rhetoric of life. In contrast I suggest that we can, once again, rehistoricize and resynthesize the logic-grammar-rhetoric of the structural-functionalphenomenal levels of empirical scientific analysis. Instead of the sudden magic of a phase transition, it is the long evolutionary history of the signifying relations of exchange that links these seemingly different levels of analysis. I suggest, for example, that the logic of exchange-what Kauffman calls chemical interactions-evolves the grammar of exchange-what Kauffman calls the genetic template-which evolves the rhetoric of exchange-what Kauffman calls metabolic autocatalysis. And of course, in turn, the metabolic rhetoric of exchange evolves the genetic grammar of exchange which evolves the chemical logic of exchange. In other words, these seemingly different levels-dimensions-scales and velocities of exchange loop back on themselves over and again down the 
ages and evolve the co-incidental micro-medianmacro eco-matrices of exchange. And so we don't have to evoke the sudden magic of phase transitions, the sudden magic of phenomenal consciousness, the sudden magic of emergent properties in order to leap from one spatialized level of analysis to another. Instead, we can trace the long evolutionary history of the signifying relations of exchange that links the relative-complex-reflexive algorithms of exchange.

Instead of conjuring the phenomenal magic of emergent properties from the structural science of complex systems-I am thinking here of the work of Gell-Mann, (QJ, 1994), Kauffman (AHU, 1995), Lewin $(C, 1992)$ and all their heirs at the Santa Fe Institute-I am suggesting that we can outline the long evolutionary history of the relative-complexreflexive algorithms of exchange. We can trace the step-by-step algorithmic sequences that connect the logic-grammar-rhetoric of the structural-functionalphenomenal signifying relations of exchange. We can recognize how these algorithmic sequences loop back on themselves and evolve the rhetoric-grammar-logic of the phenomenal-functional-structural signifying relations of exchange. And so we can trace the varied ways in which some of the relatively less complexly reflexive co-incidental micro-median-macro ecomatrices of the signifying relations of exchange evolve some of the relatively more complexly reflexive co-incidental micro-median-macro ecomatrices of the signifying relations of exchange. Of course that does not mean that evolutionary history is always progressing toward higher and higher levels of relativity-complexity-reflexivity. And of course that does not mean that evolutionary history is always proceeding at the slow pace of the tortoise. In fact, evolutionary history sometimes proceeds at the fast pace of the hare-but we don't have to pull a rabbit out of our hat in order to explain that fast pace. Instead, we can trace the long evolutionary history of the signifying relations of exchange which loop back on themselves over and again down the ages and evolve countless varieties of relative-complex-reflexive algorithms.

Instead of a phenomenal-structural theory of the emergence of complexity, therefore, I am proposing an evolutionary-historical theory of the evolution of relativity-complexity-reflexivity. That is, we have to argue that complexity magically "emerges" from an "adaptive system" only when we freeze and frame the signifying relations of exchange in the spatialized grids of enlightened, empirical science. Instead, I suggest we can recontextualize the evolution of complexity within the long evolutionary history of the relative-complexreflexive algorithms of exchange. If the evolutionary history of this universe is a nearly fourteen billion year long narrative of energy and entropy, order and chaos, life and death, then how do we get from the relatively less complexly reflexive signifying relations of quantum exchange to the relatively more complexly reflexive signifying relations of genetic exchange? The extended metaphor of the so called phase transition of the so called emergence of complexityi.e. the phenomenal leap from one spatialized level of analysis to another-actually jumps over the question of the evolutionary-historical connections linking the relatively less complexly reflexive coincidental micro-median-macro eco-matrices of the signifying relations of exchange to the relatively more complexly reflexive co-incidental micro-medianmacro eco-matrices. That extended metaphor makes it sound as if the evolutionary dynamic is, well, magical and mystical. Instead, I suggest it is historical and algorithmic. I suggest that it is the long evolutionary history of the algorithms of exchange that evolve and link the relatively less complexly reflexive coincidental micro-median-macro eco-matrices of the signifying relations of exchange to the relatively more complexly reflexive co-incidental micro-medianmacro eco-matrices. In short, the evolutionary history of relativity-complexity-reflexivity can be defined in terms of the evolutionary history of the relativecomplex-reflexive algorithms of exchange. Instead of repeating the magical incantations of magical formulas, we can trace the evolutionary histories of evolutionary algorithms.

In this particular evolving universe, for example, the new relative algorithms of physical exchange-e.g. 
$\mathrm{E}=\mathrm{mc}^{2}$-looped back on themselves and evolved the new complex algorithms of chemical exchange-e.g. $\mathrm{H}_{2}+\mathrm{O}=$ Water-which looped back on themselves and evolved the new reflexive algorithms of biological exchange-e.g. DNA + DNA = Cells. And as these new relative-complex-reflexive algorithms looped back on themselves they evolved the metabolism of exchangeor what we can now define as the co-incidental ecomatrix of life. In turn, the new relative-complexreflexive algorithms of physical-chemical-biological exchange looped back on themselves and evolved the new relative algorithms of sensory exchange-e.g. Stimulus + Response $=$ Reactive Behavior - which looped back on themselves and evolved the new complex algorithms of synaptic exchange-e.g. Link + Link $=$ Ruled Behavior-which looped back on themselves and evolved the new reflexive algorithms of neural exchange-e.g. Pathway + Pathway $=$ Recursive Behavior. And as these new relative-complexreflexive algorithms looped back on themselves they evolved the consciousness of exchange-or what we can now define as the co-incidental eco-matrix of mind. In turn again, the new relative-complexreflexive algorithms of physical-chemical-biological exchange and sensory-synaptic-neural exchange looped back on themselves and evolved the new relative algorithms of logical exchange-e.g. Gesture + Vocalization $=$ Signifier-which looped back on themselves and evolved the new complex algorithms of grammatical exchange-e.g. Signifier + Signifier $=$ Syntax-which looped back on themselves and evolved the new reflexive algorithms of rhetorical exchangee.g. Syntax + Signification $=$ Semantics. And as these new relative-complex-reflexive algorithms of exchange looped back on themselves they evolved the articulations of exchange-or what we can now define as the co-incidental eco-matrix of language. And, more probably, the reflexive neural exchanges of mind and the reflexive recursive exchanges of language evolved together. Similarly, these logicalgrammatical-rhetorical cycles of exchange looped back on themselves and evolved the rhetoricalgrammatical-logical cycles of exchange.
In sum, the relative-complex-reflexive algorithms of physical-chemical-biological exchange looped back on themselves and evolved the relative-complex-reflexive algorithms of sensory-synaptic-neural exchange which looped back on themselves and evolved the relative-complex-reflexive algorithms of logicalgrammatical-rhetorical exchange. And yet, time and again, we stop at the critical juncture of the relative algorithms and the complex algorithms of exchange when we should take the next step and recognize the reflexive algorithms of exchange. In contrast, I suggest that we arrive at life-mind-language and, on another level, nature-culture-history, only when the relative algorithms of exchange and the complex algorithms of exchange loop back on themselves and evolve the reflexive algorithms of exchange. And so along with the new science of relativity and the new science of complexity I propose a new science of reflexivity. The reflexive algorithms of physical-chemical-biological exchange evolved the co-incidental eco-matrix of life; the reflexive algorithms of sensory-synaptic-neural exchange evolved the co-incidental eco-matrix of mind; the reflexive algorithms of logical-grammaticalrhetorical exchange evolved the co-incidental ecomatrix of language. In other words, the singularity of human consciousness is not so singular, rather it is part and parcel of the long evolutionary history of reflexivity. And that is precisely why I propose a new evolutionary-historical science of reflexivity.

The enlightened empirical scientists and the romantic intuitive philosophers couldn't define life-mindlanguage or nature-culture-history precisely because they are no-thing. While the analytic materialism of enlightened empirical science unlocked and exhumed critical thinking, nevertheless it also reified the signifying relations of exchange. Why? Because the non-identity of non-identity is invisible to the eye and inaudible to the ear. And so the non-identity of non-identity is very difficult to articulate in French, German, English-the dominant analytic languages of the European Enlightenment. As I have noted, even Darwin himself retreated from that radical thought. And so-without being aware of what they were 
doing-the enlightened empirical scientists reified the evolving co-incidental micro-median-macro ecomatrices of the signifying relations of exchange. They analyzed reified things in an objectified universe because that is what they saw and heard, what they touched, smelled, tasted. As a result, they stopped time, enframed space, narrowed perception with the logical ladders, grammatical tables, rhetorical flows of natural science, natural history, natural philosophy. And they often summarized their remarkable discoveries with an algorithm, or a set of algorithms.

And yet what is an algorithm, after all, except a temporal formula of exchange? The equal sign in every equation shouts: "This can be exchanged for that!" In this way the algorithm articulates the relative values of the signifiers being exchanged as well as the relative values of the signifiers initiating the exchange. In this way contemporary scientists can finally make the transition from the empirical physics of enframed objectified things to the evolutionary history of relative signifying relations. In this way I suggest that the fundamental evolutionary dynamic of the long evolutionary history of nature-culture-history can be defined as the innovative-generative repetitions of the multiplications and variations of the signifying relations of exchange and the conservative-restrictive repetitions of the selections and adaptations of the signifying relations of exchange. These innovativegenerative and conservative-restrictive signifying relations of exchange looped back on themselves over and again down the ages and evolved new evolutionary algorithms of exchange which evolved new co-incidental eco-matrices of exchange. In this context I suggest that we can redefine what Paps and Holland infer as "the minimal protein-coding genome of the first animal" as an already very late algorithmic articulation of the already very long evolutionary history of the signifying relations of exchange. Similarly, I suggest that we can redefine the neural net of the latest artificial intelligence matrix as an already very much later algorithmic articulation of the already very much longer evolutionary history of the signifying relations of exchange. In other words, instead of thinking like an Anglo-Saxon empirical philosopher, we can think like an American-Navaho evolutionary historian. That is, instead of appropriating Navaho culture, we can listen to the Navaho people.

In this context I suggest that we can take DarwinWallace-Mendel's theory a step further by recognizing that while the species, the variety, the gene are evolutionary-historical articulations of the signifying relations of exchange, they do not explain these signifying relations. Imagine if the historical linguists argued that the alphabet explained the evolution of language. I would reply that while the alphabet is an evolutionary-historical articulation of the signifying relations of exchange, it does not explain the evolution of language. And so the focus on the species, the variety, the gene reveals the reductive, analytic, materialist bias of the enlightened scientists who reduced the reified whole to the reified part-and then couldn't put Humpty Dumpty back together again. Why this bias? Because in order to liberate themselves from the spiritual speculations of scholastic theology, the enlightened scientists needed to ground themselves in the material analyses of empirical science. They needed to ground themselves in the material world that they experienced with their five senses. And, as I have noted, they made tremendous discoveries. Similarly, the enlightened scientists who continue to pursue these empirical analyses to this very day continue to make tremendous discoveries. However, as I have also noted, the newly enlightened scientists paid a heavy price for their objective, experimental, analytic investigations. They reduced science to the quest for the material origin of empirical things instead of re-imagining science as a reflection of the long evolutionary history of the signifying relations of exchange. And so it is no coincidence that the newly enlightened explorer's quest for the origin of the Nile and the Amazon, the origin of the North and the South Pole, the origin of Species and Man, etc., etc., coincided with the newly enlightened scientist's quest for the material origin of empirical things. And since most scientists are men and since most men are notoriously bad at recognizing the critical importance of signifying relationships, then 
we have the reactionary historical bias, the reactionary epistemological bias and the reactionary gender bias of the empirical science of things. No wonder, then, that the Romantic philosophers and the Romantic poets tried to put nature back together again with their intuitive evocations of the transcendental sublime. And no wonder Heidegger tried to put nature back together again with his phenomenological meditations on the emergence of being. And no wonder they failed.

In other words, I suggest that instead of enframing and universalizing the enlightened world of hard empirical facts, or the romantic world of soft transcendental visions, or the postmodern world of plastic deconstructive simulations, we can rehistoricize and critique the postmillennial world of the signifying relations of exchange. In this context I suggest that the signifying relations of exchange link the nature of nature, the nature of culture, the nature of history in a continuous evolutionary-historical narrative or, rather, in a continuous series of localglobal-universal evolutionary-historical narratives that are neither coordinated in space, nor synchronized in time. That is, evolutionary history does not evolve everywhere in the same way, at the same time, in the same stages. As Einstein suggested, space-time is relative. Life evolved here on earth, for example, over three billion years ago, but we have no idea where else or when else it might also have evolved. Similarly, one culture and one generation articulates some ecomatrices of the signifying relations of exchange and another culture and another generation articulates other eco-matrices. And while some of these cultures, generations, eco-matrices overlap, nevertheless that does not guarantee that they are coordinated in space or synchronized in time. As a result, tremendous conflicts and contradictions emerge from the competitive and cooperative practices of exchange-signification-value. And that is precisely why evolutionary history cannot just be analytic, empirical, descriptive, but must also be synthetic, critical, reflexive. The conflicts and contradictions of culture are not only natural and inevitable, but also cultural and historical. Marx was catastrophically wrong about many things, but he was exactly right when he said, "Men make their own history, but they do not make it as they please; they do not make it under circumstances of their own choosing..." (EB, 9). And so we must reflexively critique the varied ways in which women and men make their own history-the varied ways in which we embody, enact, evolve the dynamic-practice-syntax of exchange.

$$
* * * * * * * * * *
$$

Just as the theories of the origin of nature confuse the articulations of evolutionary history with the dynamics of evolutionary history, so too the theories of the origin of culture confuse the articulations of evolutionary history with the practices of evolutionary history. They confuse the articulations with the explanations. As I have suggested, the long evolutionary history of the signifying relations of exchange evolved the so called genus and species Homo sapiens and then, in turn, the so called genus and species Homo sapiens evolved the long evolutionary history of the signifying relations of exchange. That is, the signifying relations of exchange evolved the evolutionary algorithms of exchange which evolved the co-incidental eco-matrices of modern human beings and modern human culture. In this context I suggest that the long evolutionary history of the cumulative advantages of the particular ratios of the innovative-generative repetitions and the conservative-restrictive repetitions of the relativecomplex-reflexive algorithms of the signifying relations of exchange evolved modern human beings and modern human culture.

Homo sapiens, as a modern species with a modern culture, therefore, did not only appear with a shift in climate; a thinning of the forest; a descent from the trees; a longer pair of legs; a bipedal gait; an erect stance; a freer pair of arms and hands; a narrower stomach; a shorter jaw; a smaller set of teeth; a flatter face; a bony middle ear; a larger fissured brain; a synaptic matrix; a scavenging-foraging family; a mastery of tools; a control of fire; a harvest of seafood; a facility with projectile weapons; a hunting-gathering 
band; a higher protein diet; a genetic mutation; a neural reorganization; a cognitive awareness; a behavioral adaptability; a linguistic fluency; an innovative creativity; a division of labor; a surge in population; a denser demographics; a warring-bartering tribe; a more efficient immune system; a collective capacity to imitate, learn, adapt; an improved memory; a totemic clan; a prohibition of incest; a requirement of exogamy; a lineage system; a kinship altruism; a reciprocal altruism; a structural logic; a functional grammar; a phenomenal rhetoric; a genetic bio-logic; a modular psycho-grammar; a memetic socio-rhetoric; an ability to think, plan, imagine; a proficiency with mythic, religious, dramatic narratives; a readiness for abstraction, representation, symbolization; a talent for painting, music, art; a herding-farming settlement; a trading-meeting village; a market-festival town; a manufacturing-commercial city; a channeling of energy flows; an increasing complexity; a gathering and reading of information, etc., etc. Klein cites several of these theories of the origin of culture and I have added several more from different fields of study. While each one of these theories evoke a different factor of evolutionary history, none of them actually explain the dynamic-practice-syntax of evolutionary history.

In contrast, I suggest that Homo sapiens as a modern species with a modern culture evolved via the long evolutionary history of the cumulative advantages of the particular ratios-what we can call the Quixt Ratios-of the innovative-generative repetitions and the conservative-restrictive repetitions of the mutually reinforcing successes of the relative-complexreflexive algorithms of the signifying relations of exchange. These evolutionary algorithms selected for the synergistic relativity of social individuals with social skills; they selected for the synergistic complexity of social individuals with social brains; they selected for the synergistic reflexivity of social individuals with social minds-and so they evolved the relative-complex-reflexive co-incidental eco-matrices of modern human beings and modern human cultures. In this context we can return to our earlier argument and recall our definition of life as a relative-complexreflexive co-incidental eco-matrix of the metabolic dynamic of exchange; our definition of mind as a relative-complex-reflexive co-incidental eco-matrix of the neural dynamic of exchange; our definition of language as a relative-complex-reflexive co-incidental eco-matrix of the recursive dynamic of exchange. The hard-nosed empirical philosopher who argues that consciousness in and of itself does not exist ought to argue, if he were consistent, that life-mind-language in and of themselves do not exist. Of course, lifemind-language do not exist in and of themselves as empirical objectified things precisely because they are further articulations of the long evolutionary history of the relative-complex-reflexive signifying relations of exchange. The signifying relations of life-mindlanguage evolved various social groups and various social groups evolved the signifying relations of lifemind-language. And of course these social groups offered enormous adaptive advantages over the isolated lives of isolated individuals.

Klein states that, "If we accept that modern human behavior provided the competitive advantage that allowed modern humans to spread from Africa, it remains uncertain what promoted behavioral advance. Did it follow strictly on social, economic, or technological change, as most specialists believe, or was it sparked by a neurological change that fostered fully modern cognitive ability?" (HC, 721-2). However, instead of choosing between the alternatives of either social-economic-technological change or geneticneural-psychological change as the explanation for the origin of culture, I am suggesting that the signifying relations of exchange evolved the evolutionary algorithms of exchange which evolved the Quixt Ratios of exchange which evolved the sustainable, co-incidental, micro-median-macro eco-matrices of exchange which we objectify as nature-culturehistory. They evolved, for example, new signifying relations of energy and matter, time and space, stars and planets, earth and air, fire and water. They evolved life-mind-language. They evolved families-bandstribes, villages-towns-cities, kingdoms-nations-states. 
They evolved obligations-ethics-rules, rights-dutieslaws, rituals-traditions-institutions. They evolved myths-epics-dramas, religions-politics-philosophies, natural sciences-social sciences-humanities. They evolved evolutionary histories. They evolved sentence after sentence, including the very sentences in this very text and including this very sentence. And so, yes, this very study is no-thing more and no-thing less than a further articulation of the long evolutionary history of the relative-complex-reflexive algorithms of the signifying relations of exchange. This very study is no-thing more than a co-incidental eco-matrix of the signifying relations of exchange.

Of course, the evolutionary-historical articulations of the signifying relations of exchange evolved more slowly or more quickly depending upon the minor or major, slow or fast changes in the selection criteria which evolved, and which were evolved by, the evolutionary algorithms of exchange. That is, the evolutionary-historical velocity of these evolutionaryhistorical innovations depended upon the various catalysts of evolution, the various selection criteria of evolution, the various evolutionary algorithms of evolution, the various Quixt Ratios of evolution, etc., etc. They depended upon how long the particular innovative-generative signifying relations of exchange could be repeated and sustained and how long the particular conservative-restrictive signifying relations of exchange could be repeated and sustained. In short, the four R's-relations-repetitions-ratiosreflexivity-are critical to the long evolutionary history of the co-incidental micro-median-macro eco-matrices of exchange. And so, for example, the evolutionary algorithms of natural selection evolved the evolutionary algorithms of cultural selection which evolved the evolutionary algorithms of historical selection. In turn, the consequent evolution of the-relative-complex-reflexive-co-incidental-ecomatrix-of-the-signifying-relations-of-exchange-thatwe-call-consciousness means that we cannot reduce the evolutionary algorithms of historical selection to the evolutionary algorithms of cultural selection to the evolutionary algorithms of natural selection-that is the scientistic mistake that the social darwinists, behavioral psychologists, sociobiologists, etc., etc., make. Again, instead of searching for the mythic origin of nature-culture-history, I suggest we can trace the long evolutionary history of the signifying relations of exchange which evolve the evolutionary algorithms of exchange which evolve the Quixt Ratios of the sustainable, co-incidental, micro-median-macro eco-matrices of exchange.

In this context the new reflexive possibilities of symbolic representation, linguistic expression, technological sophistication evolved with, in, through our so called species. The genetic bottleneck of our so called species which occurred approximately 70,000 to 60,000 years ago-caused, perhaps, by a prolonged drought-was also a cultural bottleneck. That is, the few tens of thousands or so fertile Homo sapien couples who came through the genetic bottleneck may have survived precisely because they were already in the process of evolving the signifying relations of exchange which were already in the process of evolving the evolutionary algorithms of exchange which were already in the process of evolving the co-incidental eco-matrices of exchange that we call culture. Instead of evolving the bigger teeth of the saber-tooth tiger, our ancestors evolved the sustainable co-incidental ecomatrices of scavenging-foraging families, huntinggathering bands, warring-bartering tribes. In turn, they evolved the sustainable co-incidental eco-matrices of herding-farming settlements, trading-meeting villages, market-festival towns, manufacturing-commercial cities, etc., etc.

In fact, I suggest that different species evolved as different expressions of the maximizationoptimization-articulation of different sets of the genetic algorithms of exchange: e.g. the algae's color; the ant's legs; the eagle's wings, the peacock's tail, the owl's eyes, the fox's ears, the tiger's teeth, the giraffe's neck, the elephant's trunk, the chimpanzee's handsand the human's brain. These varied forms of genetic maximization-optimization-articulation cannot be explained by natural and sexual selection alone. In this context we might ask, for example, Why giraffes? 
Neither the theory of natural selection, nor the theory of sexual selection offer any positive explanation as to why giraffes exist. And yet I suggest that a theory of the algorithmic exuberance of the signifying relations of exchange explains that giraffes exist because, like other species, they maximize-optimize-actualize particular sets of particular genetic algorithms. In other words, nature poses the same question over and again: What if we maximize-optimize-actualize the set of genetic algorithms for, respectively, color, legs, wings, tails, eyes, ears, teeth, necks, trunks, handsand brains?

Aristotle and Darwin both sensed the algorithmic exuberance of nature when they argued for the teleological drive toward the perfection of form, but their teleological arguments, as teleological arguments, reveal that their respective natural histories were too much indebted to Plato's supernatural myth. They both suggested that the imperfect grammatical forms of the natural world were striving toward the perfect logical essences of the supernatural world. In contrast, I am not arguing for the teleological drive toward the perfection of form, rather I am arguing for the algorithmic exuberance of genetic articulation. And so while the morphology of the primate body of Homo sapiens has been relatively stable for about 200,000 years, that doesn't mean that it isn't still evolving. In fact, our bodies and our minds are still evolving together. The nutritional health benefits and the educational social benefits of some cultures, for example, have evolved stronger, taller, larger human body forms along with more literate, numerate, technological human cognitive forms. And yet, as Darwin notes in The Descent of Man (1871), these kinds of evolutionary distinctions are the byproduct of the socio-economic selection processes of different socio-ecologies-and not an expression of any supposed innate superiority or inferiority of race. In other words, the radical implications of the radical theory of the evolution of no-thing-ness explodes the conservative myth of the essential identity of race-and therefore of racism. While Darwin does not pursue the radical implications of his radical theory in $\mathrm{On}$ the Origin of Species, nevertheless he does return to one of those radicals implications-i.e. the explosion of the conservative myth of racism-with great effect in The Descent of Man. And yet, after the firestorm of public controversy sparked by his broadly conceived evolutionary narratives, Darwin withdrew to the peace and quiet of his narrowly defined empirical studies. He wrote one monograph on emotions, seven monographs on plants and animals and a final monograph on the ecological impact of earthworms.

In any case, the more recent archaeological discoveries of evolutionary anthropology lead to a further question: If the modern morphology of Homo sapiens had already evolved about 200,000 years ago, then why did the modern anthropology of Homo sapiens only emerge about 70,000 to 50,000 years ago? What took so long? I suggest it took another 150,000 years for the signifying relations of exchange to evolve the evolutionary algorithms of exchange which evolved the Quixt Ratios of exchange which evolved the sustainable co-incidental eco-matrices of exchange that we call modern human culture. That is, it took another 150,000 years for the relative algorithms of exchange to evolve the complex algorithms of exchange and for them to evolve the reflexive algorithms of exchange. I suggest it took another 150,000 years for the algorithms of an articulate, acculturated, reflexive human community to evolve.

And, yet again, with that new expression of evolutionary relativity-complexity-reflexivity, the analytic narratives of nature must necessarily merge with and must necessarily evolve into the synthetic narratives of culture and history. And, yet again, that is the critical shift in historical consciousness that the social darwinists, behavioral scientists, sociobiologists, etc., etc. fail to make. They reduce the reflexive syntax of historical exchange to the complex practice of cultural exchange to the relative dynamic of natural exchange. They reduce recursive behavior to ruled behavior to reactive behavior. They reduce the rhetoric of history to the grammar of culture to the logic of nature: i.e. mathematics, physics, chemistry; genetics, cybernetics, memetics; cosmology, ecology, 
climatology; biology, demography, neurology; etc., etc. Of course the reduction of the rhetoric of history to the grammar of culture to the logic of nature has generated many deep insights. And yet I suggest that the study of an articulate, acculturated, reflexive human community requires a further advance. It requires the re-integration of the logic-grammarrhetoric of nature-culture-history in reflexive, critical, postmillennial evolutionary-historical narratives of the signifying relations of exchange.

If the Quixt Ratios of exchange slid too far toward the innovative-generative range of multiplication and variation, for example, then the practices of exchange couldn't evolve a sustainable communal synergy-they would be too dynamically unstable. If the Quixt Ratios of exchange slid too far toward the conservativerestrictive range of selection and adaptation, then the practices of exchange couldn't evolve an adaptable communal synergy-they would be too rigidly stable. And who knows how many hominin gatherings failed to evolve a flexible-yet-stable and a stable-yetflexible communal synergy and so disappeared from history? Who knows how many hominin gatherings failed to evolve the precise ratios of exchange that led to the adaptive advantages of cultural survival? The lost histories of the lost are as important to the evolutionary narratives of evolutionary history as the found histories of the found. They are the missing evolutionary algorithms-the deselected evolutionary algorithms-in the optimization protocols of exchange.

As Klein notes, the archaeological record reveals that the Neanderthals made the same heavy stone hammers and the same thick stone blades millennia after millennia. And so I suggest that the Quixt Ratios of the Neanderthal signifying relations of exchange slid toward the conservative-restrictive range of selection and adaptation and, as a result, the evolution of a reflexive Neanderthal culture slowed to a crawl. In contrast, I suggest that the Quixt Ratios of the Homo sapien signifying relations of exchange slid toward the innovative-generative range of multiplication and variation and, as a result, the evolution of a reflexive Homo sapien culture quickened to a race. And perhaps the Neanderthals could have emerged from the cul de $s a c$ of their too conservative-restrictive Quixt Ratios of exchange-except they ran out of time. Wave after wave of Homo sapiens followed the Neanderthals out of Africa and into the Near East and Europe. They bred with them, competed with them and perhaps even wiped them out with some kind of pandemic disease. Perhaps the few ten thousands or so fertile Homo sapien couples who came through the genetic bottleneck of about 70,000 years ago were not only the acculturated survivors of a prolonged drought, but also the acculturated survivors of some kind of pandemic influenza. And perhaps that acculturated sub-speciesprecisely because of their more innovative-generative Quixt Ratios of exchange-were able to evolve a solution to the drought and a resistance to the disease. Perhaps, for example, they were able to evolve more sustainable practices of mutual aid. We often forget that the social exchanges of inclusive cooperation are as powerful an evolutionary force as the social exchanges of exclusive competition.

And so perhaps when the much larger population of the much more innovative-generative Homo sapiens first came into contact with the much smaller population of the much less innovative-generative Neanderthals, they brought some kind of pandemic influenza with them. As Houldcroft and Underdown suggest, "The transfer of pathogens between hominin populations... may also have played a role in the extinction of the Neanderthals..." (AJPA, 04/10/16). And so perhaps the Neanderthals died out as a result of their much too conservative Quixt Ratios, their much too different immune systems, their much too limited practices of mutual aid. As a result, the Neanderthals only survive as traces in one to four percent of modern human DNA. And yet the fate of the Neanderthals requires us to consider the fate of our own so called species. Have the Quixt Ratios of contemporary culture become, once again, unsustainable? Have they split down the middle and slid to the extremes? Have our innovativegenerative technologies of exchange become too flexible and unstable? Have our conservativerestrictive institutions of exchange become too stable 
and inflexible? In other words, as I have suggested, we must write the evolutionary histories of the signifying relations of exchange in a hermeneutical mirror.

We have only begun to explore the radical implications of our new general theory of evolution and our new general theory of evolutionary history. We have only begun to trace the long evolutionary history of the signifying relations of exchange. We have only begun to explain how the signifying relations of exchange evolve the evolutionary algorithms of exchange which evolve the eco-matrices of exchange. And yet we have shifted the study of nature-culturehistory from the search for a theory of every-thing to the discovery of a theory of no-thing.

\section{References}

Darwin, Charles. On the Origin of Species. Oxford: Oxford UP, 1998.

—. The Descent of Man. London: Penguin Classics, 2004.

Derrida, Jacques. Given Time I.: Counterfeit Money. Chicago: U of Chicago Press, 1992.

Foucault, Michel. The Order of Things. New York: Vintage, 1973.

Gell-Mann, Murray. The Quark and the Jaguar. New York: W.H. Freeman \& Co., 1994.

Henig, Robin Marantz. The Monk in the Garden. New York: Mariner, 2001.

Houldcroft, Charlotte J. and Underdown, Simon J., "Neanderthal Genomics Suggests a Pleistocene Time Frame for the First Epidemiologic Transition." American Journal of Physical Anthropology (04/10/16), URL = < HTTPS://doi. org/10.1002/AJPA.22985>.

Kauffman, Stuart. At Home in the Universe. Oxford: Oxford UP, 1995.

Klein, Richard. The Human Career. Chicago: U of Chicago Press, 2009.

Lamarck, Jean de. Zoological Philosophy. Ithaca: Cornell UP, 2009.
Lewin, Roger. Complexity. New York: Macmillan, 1992.

Lévi-Strauss, Claude, The Elementary Structures of Kinship. Boston: Beacon Press, 1969.

Linné, Carl. A General System of Nature. London: Lackington, Allen \& Co., 1802.

Marx, Karl. The Eighteenth Brumaire of Louis Bonaparte. New York: Foreign Language Press, 1984.

Mendel, Gregor. Experiments in Plant-Hybridisation. London: Forgotten Books, 2017.

Paps, Jordi and Holland, Peter W.H., "Reconstitution of the Ancestral Metazoan Genome Reveals an Increase in Genomic Novelty." Nature Communications (04/30/18), URL = $<$ HTTPS:/Nature.Com/articles/s4146-018-04136-5.ris/>.

Rheinberger, Hans-Jörg; Müller -Wille, Staffan; Meunier, "Gobert, "Gene." The Stanford Encyclopedia of Philosophy (Spring 2015 edition), E.N. Zalta (ed.), URL = $<$ HTTPS://Plato.Stanford.edu/archives/spr2015/entries/ gene/>.

Young, Robert and Morgan, William. The Navajo Language. Flagstaff: Native Child Dinétah, 2014.

-. A Vocabulary of Colloquial Navajo. Flagstaff: Native Child Dinétah, 2014. 